\title{
TRABALHO, EDUCACC̃̃O E SOCIEDADE: PRÁTICAS PEDAGÓGICAS E FORMAÇÃO DO EDUCADOR
}

\author{
WORK, EDUCATION AND SOCIETY: PEDAGOGICAL \\ PRACTICES AND THE TRAINING OF THE EDUCATOR \\ LE TRAVAIL, L'ÉDUCATION ET LA SOCIÉTÉ : \\ PRATIQUES PÉDAGOGIQUES ET FORMATION DE L'ÉDUCATEUR \\ TRABAJO, EDUCACIÓN Y SOCIEDAD: \\ PRÁCTICAS PEDAGÓGICAS Y FORMACIÓN DEL EDUCADOR
}

Maria Eugênia Castanho *

\section{RESUMO}

O texto relata pesquisa que tem por objetivo estudar as complexas relações entre trabalho e educação superior, visando apontar pistas para um trabalho docente de qualidade. Foi investigado um curso que funciona no periodo integral (diurno) e no periodo noturno, numa universidade de grande porte na regiāo de Campinas/SP, tendo sido ouvidos alunos concluintes e docentes. O principal foco da pesquisa foi o aluno trabalhador. Os resultados mostraram que, de modo geral, não se alia a atividade didática com a realidade do trabalho, permanecendo ambas como mundos separados. Conclui-se que há medidas que podem ser adotadas para que melhore a qualidade do ensino universitário dos trabalhadores-estudantes. Palavras-chave: Trabalho e educação superior. Estudante-trabalhador. Qualidade de ensino.

* Doutora em Educação pela Universidade Estadual de Campinas (1989). Professora e pesquisadora junto à Pontifícia Universidade Católica de Campinas. Bolsista do CNPq (meu@dglnet.com.br). 


\section{INTRODUÇÃO}

O presente texto vincula-se a projeto de igual denominação desenvolvido por mim nas atividades de investigação a que procedo na instituição de origem. No referido projeto destaco:

A presença cada vez maior, nos cursos superiores, de estudantes que exercem atividade profissional remunerada vem colocando questôes novas e sérias à reflexão pedagógica e à prática docente (CASTANHO, 2007, p. 2).

Quanto à metodologia, no texto podem ser detectados pontos que levam ao desvelamento da abordagem teórica privilegiada para o tratamento do tema (CASTANHO, 1989; FRIGOTTO, 2002 e 2004; GENTILI, 2002; LOMBARDI; SAVIANI; SANFELICE, 2002). Referida abordagem é a do historicismo dialético. As unidades significativas da pesquisa serão buscadas na história vivida das sociedades através de um sustentáculo teórico definido (ou seja, o do historicismo dialético) cujas categorias são: contradição, totalidade, reprodução, mediação e hegemonia.

Para examinar a questão em pauta, propus-me investigar um determinado curso numa instituição de grande porte na cidade de Campinas:

O presente projeto busca estudar as complexas relações entre trabalho e educação superior, centrando-se num caso exemplar: o curso de Enfermagem, que funciona em dois períodos distintos: integral e noturno.

Com efeito, nesse período foram ouvidos 123 alunos concluintes, dos quais 58 do período integral e 65 do período noturno, e 11 docentes (de um total de 33), aplicandose-lhes questionários sobre a problemática investigada. Coerentemente com o que previa o projeto original, foram aplicados aos discentes e docentes dos dois períodos questionários semi-estruturados, com perguntas abertas e fechadas. No entanto, dada a riqueza do material coletado por essa via, não foi necessária a realização de entrevistas com sujeitos selecionados nos respectivos universos. É de salientar que o material referente aos docentes, enviado e coletado por meio eletrônico, acabou funcionando como entrevista.

De mesmo passo, e atendendo ao que previa o projeto, foi feita a análise com base em amplo referencial teórico.

Cabe apontar que o trabalho contou com a participação de um bolsista de Iniciação Científica (Pibic), que veio sendo preparado para o quefazer acadêmico, envolvendo-se diretamente com os procedimentos de pesquisa. 


\section{FUNDAMENTOS TEÓRICO-METODOLÓGICOS}

O mundo do trabalho mudou substancialmente nas últimas décadas. Mas isso não significa que o trabalho tenha perdido centralidade na sociedade capitalista em que o planeta como um todo vive, sendo que mesmo as exceções, como as de algumas regiões da África ou da floresta amazônica, confirmam a regra, pois acabam por se submeter à lógica do capital por subordinação. A regra de ouro descoberta pelos economistas liberais e retomada por Marx numa perspectiva crítica, regra essa segundo a qual o trabalho é o princípio do valor, continua plenamente vigente. $\mathrm{Na}$ sociedade capitalista, o capital se origina do trabalho ou, se preferirmos, vive da exploração do trabalho. $\mathrm{O}$ trabalho não pode, por princípio, deixar de ser central numa sociedade regida pelo capital. O trabalho muda de características, flexibiliza-se, precariza-se, mas não deixa de ser central. A melhor comprovação dessa asserção está no exemplo dado por Ricardo Antunes e Márcio Pochmann:

[...] o país que mais cresce hoje em termos capitalistas, em escala global, é a China. Ela tem uma força de trabalho de mais de 800 milhōes de pessoas, o que permite o rebaixamento da remuneração da força de trabalho a um nível antes inimaginável (ANTUNES; POCHMANN, 2007, p. 4).

Uma das primeiras aproximaçōes analíticas referentes às profundas mudanças no mundo do trabalho, sem embargo da continuidade de sua centralidade no mundo capitalista, foi feita por Harry Braverman. A primeira edição de seu hoje clássico Trabalho e Capital Monopolista, em inglês Labor and Monopoly Capital: The Degradation of Work in the Twentieth Century, data de 1974, editado pela Monthly Review Press de New York. A tradução em português no Brasil veio a lume três anos depois (BRAVERMAN, 1977).

Braverman dá a sua maior contribuição ao desenvolvimento da análise sobre o trabalho no capitalismo monopolista (tema para cujo trato recorre diretamente a Marx, pois - entende - os marxistas posteriores pouco se dedicaram à questão) na quarta e na quinta partes de seu livro, denominadas, respectivamente, "A crescente diversificação da classe trabalhadora" e "A classe trabalhadora".

O trabalho em escritórios, por exemplo, é visto como um produto típico do capitalismo monopolista e, ao contrário do que pensa a sociologia convencional, não criou uma "classe média" de "colarinhos brancos" (os White Collars de Wright Mills), mas um novo proletariado. Como nas fábricas, esses escriturários proletários executam trabalho manual e funcionam nos limites de sua rotina. Também em relação à prestação de serviços e pequeno comércio houve a proletarização do trabalhador. $\mathrm{O}$ capitalismo monopolista transformou em mercadoria toda forma de atividade do ser humano, até mesmo o que as pessoas faziam para elas próprias e não para o mercado, como as atividades domésticas. A previsão de Braverman, há mais de 30 anos, era a de que os trabalhadores em lojas comerciais viriam com o tempo a se assemelhar aos operários de 
fábrica. Quem hoje vai a um shopping center num domingo e observa a precariedade do trabalho dos lojistas logo percebe o quanto de "profecia científica" havia nas análises de Braverman. Que dizer então do trabalho de um "chapista" ou de um tirador de café de lanchonete?

Mas é na seção sobre qualificação profissional da quinta parte que Braverman mais contribui para nosso específico objeto - a formação do trabalhador na educação superior. Baseado em levantamentos feitos nos Estados Unidos à época da preparação do livro, Braverman chega à desconcertante conclusão (para aquele momento, bem entendido) de que, longe de estar sendo qualificado, o trabalhador está na verdade sendo deteriorado. Pelo menos essa era a palavra utilizada à época. Hoje se diz que ele está sendo precarizado. Segundo o autor, o trabalhador não deixa de ser "ensinado", mas o é "para exclusivamente as exigências do capital” (BRAVERMAN, 1977, p. 378). Há uma certa ironia no autor quando constata:

"O trabalhador pode continuar uma criatura sem conhecimento ou capacidade, simplesmente uma 'mão' pela qual o capital faz o seu trabalho, mas tão logo ele ou ela seja apropriada às necessidades do capital, o trabalhador já não mais pode ser considerado ou chamado não qualificado" (BRAVERMAN, 1977, p. 378).

Há nessas considerações algo de Gramsci, quando reclama uma formação "politécnica" para o trabalhador, com domínio dos princípios fundamentais da ciência e da tecnologia modernas (MANACORDA, 1990).

Para nós, que discutimos a questão da educação e do trabalho, tais considerações são fundamentais. Principalmente se levarmos em conta que um percentual muito elevado de estudantes da nossa universidade, especialmente os que seguem seus cursos no turno da noite, é de trabalhadores. No levantamento que vimos de fazer no curso de Enfermagem, os concluintes do noturno, na sua quase totalidade $(92,2 \%)$, trabalham em atividades remuneradas, já na área de Saúde (76,6\%), ou em outras áreas (15,6\%), ficando fora desse contingente apenas $7,8 \%$, talvez por não-emprego ou desemprego. Esses números tornam-se ainda mais contundentes se pensarmos nos concluintes do período integral, que em princípio deveriam dedicar-se exclusivamente ao curso. No entanto, são $37,3 \%$ os que, enfrentando toda sorte de dificuldades, exercem atividades remuneradas no tempo que logram furtar ao repouso, ao estudo extra-classe e ao lazer, trabalhando na área de Saúde $(33,9 \%)$ ou fora dela $(3,4 \%)$. Para os primeiros (do noturno) e os do período integral é que se endereçam as reflexões sobre a qualidade da educação praticada quando a escola é o outro turno do trabalho.

Cerca de 20 anos depois da obra pioneira de Braverman, o brasileiro Ricardo Antunes, discípulo do húngaro radicado na Inglaterra István Mészáros, professor em Sussex, veio a lume com Adeus ao Trabalho, título a que se seguia o subtítulo: "Ensaio sobre as metamorfoses e a centralidade do mundo do trabalho" (ANTUNES, 1995). 
A realidade observada por Antunes não deixa de ser a enfocada por Braverman, mas com novos ingredientes, frutos de uma nova guinada no velho capitalismo monopolista detectado por Marx (1985) na segunda metade do século XIX. Dessa vez, os ingredientes novos eram o neoglobalismo e o neoliberalismo, que, reconfigurando-o, não mudavam a essência do modo capitalista de produção.

O mesmo autor, depois de trabalhar fartamente com dados empíricos, evidencia "uma nítida redução do proletariado fabril, industrial, manual, especialmente nos países de capitalismo avançado". Escritos mais recentes de Antunes (2005) posicionam o Brasil nesse mesmo contexto, de sorte que as análises aqui produzidas aplicam-se igualmente aos países desenvolvidos e aos ditos "em desenvolvimento", especialmente os "emergentes", como é o caso do nosso país, ao lado da China, Rússia e Índia.

Vale a pena insistir em mais uma constatação de Antunes. Desta feita, citando Alain Bihr, constata ele que:

[...] essas diversas categorias de trabalhadores têm em comum a precariedade do emprego e da remuneração; a desregulamentação das condiçôes de trabalho em relação às normas legais vigentes ou acordadas e a conseqüente regressão dos direitos sociais, bem como a ausência de proteção e expressão sindicais, configurando uma tendência à individualização extrema da relação salarial (ANTUNES, 2005, p. 44).

Sem dúvida, na classe trabalhadora se incluem os sujeitos da presente pesquisa, os estudantes de enfermagem que vendem seu trabalho ao capital em tempo integral ou parcial, na área de Saúde ou fora dela, para fazer face à sua subsistência ou para custear seus estudos. E também está fora de dúvida o fato de que são parte dessa classe os professores desses estudantes, que vivem do trabalho que exercem em instituição de educação superior, com exclusividade ou não, podendo, dentro de certos limites impostos pela lei, prestar serviços em outras empresas, como hospitais ou clínicas.

Outro ponto a destacar é que não só o assalariamento atingiu o setor de serviços, como também houve uma interpenetração recíproca entre esse setor e o chamado "mundo produtivo". Uma mesma lógica perpassa o cada vez mais empregador setor de serviços e o cada vez menos empregador setor industrial tradicional.

Acácia Kuenzer destaca as estratégias do que ela chama de "inclusão excludente", promovida pela educação, quando inclui os indivíduos na escola, mas os exclui dos frutos da economia que eles geram pelo trabalho:

Ou a tão em moda substituição da escolarização básica por cursos aligeirados de formação profissional, que supostamente melhorarão as condiçôes de empregabilidade. Ou a certificação apenas formal conferida por muitos cursos supletivos (há exceçôes), que não conferem rigor e seriedade à formação de jovens e adultos. Ou a formação superior aligeirada em instituições superiores de idoneidade discutível; ou a formação de professores nos Institutos Superiores de Educação, em licenciaturas "quase plenas". Enfim, o conjunto das estratégias que apenas 
conferem "certificação vazia", e, por isto mesmo, constituem-se em modalidades aparentes de inclusão que fornecerão a justificativa, pela incompetência, para a exclusão do mundo do trabalho, dos direitos e das formas dignas de existência (KUENZER, 2002, p. 93).

A expressão pedagógica dessa inclusão excludente a que alude Kuenzer é a pedagogia das competências (PERRENOUD, 2000).

Os tortuosos caminhos que levam à prática pedagógica que vimos de caracterizar por via teórica tornam-se presentes nos depoimentos de inúmeros sujeitos dentre os docentes que responderam on line a nossos questionários. Da mesma forma, os caminhos e descaminhos do mundo do trabalho na atualidade e suas relaçóes com o mundo da educação superior patenteiam-se, às vezes de maneira dramática, nos posicionamentos dos concluintes do curso de enfermagem a que a seguir nos reportaremos.

\section{PERFIL E POSICIONAMENTO DOS ESTUDANTES}

Nesta investigação participaram 123 concluintes do curso de Enfermagem. É bom deixar claro que a escolha desse curso se deveu à grande incidência de trabalhadoresestudantes nos seus quadros. Ademais, exercemos em outro tempo atividades docentes nesse curso. Por tais razóes, além de captarmos a voz dos estudantes concluintes de Enfermagem em 2007, também ouvimos docentes dessa I.E.S. Estes nos forneceram elementos para avaliar a questão da docência para alunos inseridos no mundo do trabalho.

Vamos à voz dos alunos que se situam no contexto de dois mundos, o do trabalho e o da educação superior.

Responderam ao questionário 58 sujeitos do período integral e 64 do período noturno, perfazendo um total de 122 sujeitos pesquisados.

No turno diurno aproximadamente $38 \%$ dos sujeitos pesquisados exercem atividade profissional remunerada, número elevado quando pensamos que se trata de curso em período integral. Quanto ao período noturno, a grande maioria é de sujeitos trabalhadores, representando cerca de $92 \%$, enquanto apenas cerca de $8 \%$ não possuem atividade profissional. $\mathrm{O}$ número de alunos trabalhadores nos dois períodos representa $66 \%$ do total geral, sendo de apenas $34 \%$ o dos que não exercem atividade profissional. No período integral, $27 \%$ dos sujeitos possuem registro em carteira e $5 \%$ não o possuem. No período noturno, $63 \%$ possuem registro em carteira e $11 \%$ não o possuem.

Percebemos por esses números a predominância de alunos trabalhadores e - o que não surpreende diante das reflexões dos analistas trazidos a este texto - um número expressivo, embora não predominante, de empregados sem registro em carteira, engrossando o contingente dos precarizados.

Segundo os alunos, quando perguntados se a universidade tem estimulado a discussão sobre o desempenho do aluno trabalhador, as respostas positivas no período integral 
foram de $29 \%$, as negativas $59 \%$ (a grande maioria). No período noturno, apenas $14 \%$ consideram que a universidade tem estimulado tal discussão, enquanto $84 \%$ discordam, apontando que a universidade se exime desta responsabilidade, e $2 \%$ não responderam. Do total geral (122), 21\% dos sujeitos afirmam que a universidade tem estimulado essa discussão, ao passo que $72 \%$ discordam desta afirmação, e $7 \%$ se abstiveram.

Quanto ao objetivo de saber qual a opinião dos sujeitos de ambos os períodos sobre a qualidade do ensino noturno comparado com o ensino diurno - se pior, igual ou melhor -, as respostas apresentadas foram: $55 \%$ dos sujeitos julgam a qualidade do ensino noturno pior que a do diurno, $34 \%$ julgam-na igual, enquanto $6 \%$ a consideram melhor e $5 \%$ não responderam.

Do total geral (143), $50 \%$ consideraram o estudo como fonte de prazer, $41 \%$ como meio de ascensão social, e $9 \%$ não responderam.

\section{QUEM SÃO AS DOCENTES}

As docentes (todas as entrevistadas são do sexo feminino) do curso investigado ouvidas nesta pesquisa têm idade variando de 40 a 50 anos, a maioria $(63,6 \%)$ entre 40 e 45 anos. Em geral são casadas (63,6\%), registrando-se 18,8\% de solteiras e igual percentual de separadas.

O regime de trabalho docente na instituição pesquisada é um ponto crítico. Pelas respostas obtidas, apenas $18,2 \%$ das docentes estão em carreira, com 40 horas-aulas semanais. As demais $81,8 \%$ apresentam diferentes cargas horárias: 9, 18, 20, 34 e 36 horas. Considerando-se a natureza universitária da instituição, o número de docentes em carreira é pequeno, sabendo-se que os denominados horistas não têm condição de exercer atividades de pesquisa e/ou extensão. Apesar disso, a maioria (54,5\%) trabalha exclusivamente na instituição. As que possuem outro emprego além da instituição pesquisada ocupam-se na área de saúde, sendo que 18,2\% trabalham 40 horas semanais. Tais números evidenciam que as reflexões antes apresentadas sobre trabalho flexibilizado e precarizado são aplicáveis à situação em estudo.

O regime apertado de trabalho explica a pouca atenção ao aperfeiçoamento pessoal, evidenciado pelo fato de que $91 \%$ das docentes não estão freqüentando nenhum curso. Apenas uma respondeu que fazia um curso de Inglês.

As respostas à pergunta seguinte são extremamente relevantes: 63,6\%, vale dizer, quase dois terços, não pensam que o curso venha estimulando discussões sobre o desempenho dos alunos trabalhadores. Apesar disso, o trabalho que o aluno exerce tem relação com o curso que freqüenta para os mesmos $63,6 \%$ das docentes. Não há contradição. Para a maioria, os alunos trabalham na mesma área do curso, porém este não leva a discussões sobre o significado do trabalho exercido. 
Como a incidência de alunos trabalhadores é maior no curso noturno do que no integral, procuramos saber das docentes como consideravam o curso no período da noite em relação ao diurno. A dispersão foi grande: o mesmo percentual (27,3\%) considerou o noturno pior, igual e melhor do que o diurno, registrando-se $18,1 \%$ de abstenções.

\section{VOZES DOCENTES}

Pelo visto nas respostas às questôes fechadas, as docentes vêem uma separação entre o mundo do trabalho e o mundo universitário, pelo menos no nível de propostas de promover a discussão entre as duas dimensões. Mas é nas respostas às questôes abertas que se percebem nuanças a essa posição, que vale a pena aqui retomar.

A docente 10, por exemplo, acredita que a separação pode ser evitada, mediante a "valorização do trabalhador bem formado" e a "ocupação de cargos estratégicos por profissionais com formação stricto sensu". Para a mesma docente, a integração seria promovida mediante ações como:

Flexibilidade/alternativas de horários; segurança do campus principalmente à noite; redução da burocracia; e evitar o pedido de trabalhos domiciliares.

Algo já tem sido feito a favor dessa integração. Ela aponta:

Reuniōes freqüentes por períodos/série com a presença dos docentes e dois alunos representantes, para acompanhamento semestral/anual com suas demandas, incluindo um planejamento de datas das avaliações escritas, seminários etc.

Já a docente 8 manifesta-se cética quanto à promoção da integração, embora pense que a conscientização do duplo pertencimento seja benéfica:

Penso que talvez essa separação não possa ser evitada, mas sim passível de discussão e busca de métodos que motivem tanto o aluno quanto o professor na aprendizagem e no ensino. Se o problema (integração trabalho-estudo) é levantado e se o assunto é discutido e refletido com interesse de ambos, naturalmente alguma proposta vai surgir no grupo.

O que se vai percebendo, através das respostas livres, é que a questão da separação entre o trabalho e o estudo é de magnitude e que ela implica o próprio sentido da existência humana. $\mathrm{O}$ "estranhamento" entre os dois mundos requer ações positivas de aproximação, quando mais não seja pelo menos no nível da consciência. A docente 7 emite uma fala importante:

Penso que esta questão é de suma importância, uma vez que o final da vida acadêmica tem como conseqüência o mundo do trabalho, seja ele acadêmico ou não. Dessa forma, refletir sobre esse tema é extremamente relevante no sentido de percebermos as necessidades que o mundo do trabalho demanda e nos prepararmos para a relação dialética que desse processo advém. 


\section{AS VOZES NO CONTEXTO DE DOIS MUNDOS}

Analisando as respostas às questôes abertas, pudemos observar a ocorrência de intervenções classificáveis em três grandes grupos ou unidades de significação:

Separação/Estímulo. Existe a separação entre os mundos do trabalho e do estudo, e, para superá-la, é necessário adotar ações de estímulo, ou incentivo.

Separação/Flexibilidade. Existe a separação entre os mundos do trabalho e do estudo e, para superá-la, é necessário flexibilizar a carga horária, o currículo e as atividades de um modo geral.

Integração. Não ocorre a separação entre os mundos do trabalho e do estudo, existindo, ao contrário, integração entre eles.

\section{SEPARAÇÃO/ESTÍMULO}

A grande maioria dos alunos, na esteira, aliás, de nossas reflexões teóricas, vê uma separação significativa entre a realidade do trabalho e a do estudo na universidade. Tal separação, contudo, não é considerada irreversível. Para sua superação propõem intervenções positivas. Uma parte destas é classificável como de estímulo (ou incentivo). Vejamos uma fala de aluno do período integral nesse sentido:

Essa separação poderia ser evitada através do incentivo a estágios e palestras para se ter uma visão diferente de mundo. Seria uma intervenção através de aperfeiçoamento, da realização de palestras e de trabalho em conjunto de alunos que não trabalham com os trabalhadores. Penso ser necessário que sejam tratados com igualdade os trabalhadores universitários e os só universitários.

A proposta é clara: uma ação de conscientização sobre o significado atual do mundo do trabalho, como o que se contém na presente pesquisa, representaria um incentivo à integração dos dois mundos, que incluiria também uma unificação de estudantes trabalhadores e não trabalhadores.

\section{SEPARAÇÃO/FLEXIBILIDADE}

Como acabamos de ver, na primeira unidade de significação estão as respostas que, afirmando a existência de separação entre os dois mundos, enxergam possibilidade de integração através de intervenções estimuladoras. Mesmo que o tom das respostas mudasse do diurno para o noturno, havia essa possibilidade de unificação. Agora, continuaremos com respostas que afirmam a separação, vêem a possibilidade de integração, só que com outros mecanismos: os da flexibilidade. 
Uma fala, de aluno do diurno, portanto, em tese, com menos problema de disponibilidade horária que os do noturno, deixa claro o que se entende por flexibilidade:

O estudante que trabalha, principalmente se for em outra área, sofre muito porque não dispõe de tempo para estudar, e os trabalhos se acumulam. Devido à falta de experiência na área, ela deve ser suprida com mais horas de estudo. A dificuldade localizando-se na prática, ele deve ser bom na teoria, mas os horários não permitem uma dedicação satisfatória. Deve-se promover mais flexibilidade de horário e diminuir a pressão psicológica em cima dos alunos que entregam trabalhos com atraso, pois não se trata de falta de interesse e muito menos de responsabilidade.

A fala é rica. Ela pressupõe, por exemplo, que o estudante que trabalha na mesma área em que estuda leva vantagem sobre o que trabalha em outra área. Isso porque, faltando-lhe experiência (pelo trabalho) na área, esta "deve ser suprida com mais horas de estudo". Vê-se, por aí, que a flexibilidade pretendida é bem objetiva e diz respeito a horários e cobrança de resultados.

\section{INTEGRAÇÃO}

A terceira unidade de significação agrupa as respostas - em número significativamente menor do que nas outras duas unidades - dos estudantes que não vêem problemas de separação entre o trabalho e o estudo. São os "integracionistas". Desde já é importante destacar que a maior incidência deste tipo de resposta ocorre entre estudantes trabalhadores que exercem atividade na mesma área de seu curso.

Isso posto, registremos uma fala de estudante do período integral:

Visto que já trabalho na área da enfermagem como técnica, vejo que há uma integração, pois reconheço a necessidade de acrescentar o conhecimento teórico e científico já que exerço a técnica.

A resposta dispensa comentários. Ela é compatível com esta outra, também de estudante do integral:

Eu não acredito nessa separação, só acho que são mundos diferentes, e vejo a Faculdade da maneira que pode nos ajudar.

Pensariam os "integracionistas" do noturno de idêntica maneira? Somos tentados a pensar que sim. A condição de trabalho na mesma área de estudo leva à visão de integração da mesma forma, independente do período. Haja vista as três falas seguintes:

O individuo deveria relacionar seu estudo, seu aprendizado com o cotidiano do trabalho, aprimorando seus procedimentos e raciocínio.

Difícil separá-los [trabalho e estudo], a menos que a pessoa só fizesse um, ou trabalho ou estudo. A integração acontece quando os dois seguirem por um mesmo objetivo, um mesmo sentido. 
Para não haver separação, é preciso evitar que o aluno tenha um só objetivo na sua vida, ou trabalho ou estudo. Como eu, trabalhando e estudando na área de saúde (enfermagem). É útil, pois se unem alguns pontos da aula, teórica, com a prática no trabalho.

É necessário que se tenha clareza. A unidade de significação “integração" reúne pequeno número de respostas e a maioria alude a uma não-separação em virtude do exercício coincidente na mesma área de trabalho e estudo. Em geral, notou-se também nesta unidade menos criticidade no pensar.

\section{CONSIDERAÇÕES FINAIS}

As principais aproximações dos resultados da investigação empírica com as linhas de reflexão afloradas pela pesquisa teórica foram feitas no decorrer do trabalho.

Resta, nestas considerações finais, apontar as principais pistas para o trabalho docente que vise, de alguma forma, mesmo considerando as limitaçôes das vias reformadoras, a melhoria da qualidade de ensino num ambiente de (relativa?) integração entre trabalho e educação.

As respostas dos estudantes em favor de uma pedagogia que leve à maximização da experiência do trabalho no ambiente acadêmico induzem a pensar em um trabalho docente, de iniciativa tanto institucional quanto pessoal, que desenvolva a criatividade, a criticidade, a indissociabilidade entre ensino e pesquisa, sendo ele próprio criativo, crítico e investigativo. É de toda evidência que um ensino indissociável da pesquisa também o é da extensão, já que a dimensão ética do ato pedagógico, envolvida na atividade extensionista, vem sendo apontada com ênfase na literatura especializada no país e no exterior.

Profissionalizar com competência é a tarefa que se coloca, o que não significa profissionalização estreita. A proposta da educação pelo trabalho leva à desalienação e à formação da consciência social. Trata-se de concretizar a percepção do processo educativo no interior das contradições sociais, recolhendo a vida ativa dos homens na sociedade. Evidentemente, isso passa pela compreensão do novo significado do trabalho na sociedade contemporânea e, conseqüentemente, à crítica das pedagogias que transferem apenas ao esforço individual a solução para a integração do estudo com o trabalho.

Uma nova abordagem para a categoria qualidade de ensino refere-se à busca de um novo conceito que não o dicotomize de seu outro lado, a quantidade, levando em conta o ensino atual e articulando dialeticamente os determinantes macro-estruturais com as possibilidades concretas de trabalho no espaço institucional acadêmico, de sorte que o trabalhador estudante insira-se nesse ambiente com o máximo proveito e o mínimo desgaste humano. 
Chegando ao fim destas considerações, cumpre indicar que este trabalho continua. Pretendemos estabelecer um aprofundamento categorial nas relaçóes entre trabalho, educação e sociedade, no contexto da reconfiguração produtiva e laboral ocorrida universalmente e em particular no Brasil a partir das três últimas décadas do século XX. Tal situação vem provocando uma reviravolta nos padrões reflexivos, dado que as categorias teóricas consagradas desde o último terço do século XIX e que permaneceram incólumes durante grande parte do século XX já não dão conta de fenômenos como o trabalho e a educação no seio da sociedade. A fortiori, também já não conseguem um grau plausível de esclarecimento para questóes decorrentes dessas centrais, a saber, as das práticas pedagógicas e da formação de educadores.

\section{Referências}

ANTUNES, Ricardo. Adeus ao trabalho? Ensaio sobre as metamorfoses e a centralidade do mundo do trabalho. 2. ed. São Paulo: Cortez, 1995.

. Os sentidos do trabalho: ensaio sobre a afirmação e a negação do trabalho. São Paulo: Boitempo, 2005.

; POCHMANN, Márcio. O novo mundo do trabalho. O trabalho no novo mundo. Jornal da Unicamp, Campinas, n. 354, p. 9-15, abr. 2007. Disponível em: www.unicamp.br/ju. Acesso em: 4 jun. 2007.

BRAVERMAN, Harry. Trabalho e capital monopolista: a degradação do trabalho no século XX. Rio de Janeiro: Zahar, 1977.

CASTANHO, Maria Eugênia. Universidade à noite: fim ou começo de jornada? Campinas/SP: Papirus, 1989.

- Trabalho-educação e docência universitária. Projeto de pesquisa. mimeo, 2007.

FRIGOTTO, Gaudêncio. Prefácio. In: PICANÇO, Iracy; TIRIBA, Lia (Orgs.). Trabalho e educação: arquitetos, abelhas e outros tecelōes da economia popular solidária. Aparecida/SP: Idéias \& Letras, 2004. p. 9-27.

. Estruturas e sujeitos e os fundamentos da relação trabalho e educação. In: LOMBARDI, José Claudinei; SAVIANI, Dermeval; SANFELICE, José Luís (Orgs.). Capitalismo, trabalho e educação. Campinas/SP: Autores Associados, HISTEDBR, 2002. p. 61-74.

GENTILI, Pablo. Três teses sobre a relação trabalho e educação em tempos neoliberais. In: LOMBARDI, José Claudinei; SAVIANI, Dermeval; SANFELICE, José Luís (Orgs.). Capitalismo, trabalho e educação. Campinas, SP: Autores Associados, HISTEDBR, 2002. p. 45-59.

KUENZER, Acácia Zeneida. Exclusão includente e inclusão excludente: a nova forma de dualidade estrutural que objetiva as novas relaçôes entre educação e trabalho. In: LOMBARDI, José Claudinei; SAVIANI, Dermeval; SANFELICE, José Luís (Orgs.). Capitalismo, trabalho e educação. Campinas, SP: Autores Associados, HISTEDBR, 2002. p. 77-95.

LOMBARDI, José Claudinei; SAVIANI, Dermeval; SANFELICE, José Luís (Orgs.). Capitalismo, trabalho e educação. Campinas, SP: Autores Associados, HISTEDBR, 2002. 
MANACORDA, Mario A. O princípio educativo em Gramsci. Porto Alegre: Artes Médicas, 1990. MARX, Karl. Capitulo VI inédito de O Capital. São Paulo: Moraes, 1985.

PERRENOUD, Philippe. Dez novas competências para ensinar. Porto Alegre: Artes Médicas Sul, 2000. 


\section{Work, education and society: \\ pedagogical practices and the training of the educator}

Abstract

The text refers to a study that aims at the complex relations between work and higher education by pointing out means for attaining quality in the work of teaching. An investigation was made of a course that operated full-time (during the day and also in the evenings) in a big university in the region of Campinas, SP, Brazil, by interviewing teachers and graduating students. The main focus of the study was the working student. Results showed that, generally speaking, didactic activity is not related to the reality of work, both remaining in separate worlds. It was concluded that there are measures that can be adopted for improving the quality of university teaching improves, specifically in the case of working students.

Keywords: Work and higher education. Working student. Quality of teaching.

\section{Le travail, l'éducation et la société : pratiques pédagogiques et formation de l'éducateur}

Résumé

Le texte rend compte d'une recherche qui a comme objectif étudier les relations complexes entre travail et éducation supérieure, visant indiquer des pistes pour un travail d'enseignement de qualité. On a examiné un cours qui fonctionne en temps intégral (pendant le jour et aussi en soirée) dans une grande université de la région de Campinas, SP, Brésil, ayant écouté les professeurs et étudiants concluants. La recherche a focalisé principalement l'étudiant travailleur. Les résultats montrent que, d'une manière générale, l'activité didactique n'est pas reliée à la réalité du travail, les deux en permanence sont comme des mondes séparés. L'on conclut qu'il existe des mesures qui peuvent être adoptées pour que la qualité de l'enseignement universitaire s'améliore.

Mots clefs : Travail et éducation supérieure. Étudiant travailleur. Qualité de l'enseignement.

\section{Trabajo, educación y sociedad: prácticas pedagógicas y formación del educador Resumen}

Esta investigación tiene el objetivo de estudiar las complejas relaciones entre trabajo y educación superior, visando apuntar pistas para un trabajo docente de calidad. La investigación se pasó en una carrera de periodo integral y nocturno en una universidad de Campinas, SP, Brasil, donde fueron entrevistados alumnos en final de carrera y docentes, enfocando principalmente el alumno trabajador. Los resultados apuntaron que, en general, no se alia la actividad didáctica con la realidad del trabajo, permaneciendo ambos como mundos separados. Se concluyó que hay medidas que pueden ser adoptadas para que mejore la calidad de la enseñanza universitaria de los estudiantes trabajadores.

Palabras-clave: Trabajo y educación superior. Estudiante trabajador. Calidad de la enseñanza.

Recebida I ${ }^{\mathbf{a}}$ versão em: 06.10.2008

Aceita $2^{\mathrm{a}}$ versão em: 06.02.2009 